\title{
Vida que não merece viver: articulações sobre abandono escolar e masculinidades negras*
}

DOI: https://doi.org/10.18046/recs.i31.3425

\author{
Vida que no merece vivirse: articulaciones sobre abandono \\ escolar y masculinidades negras \\ Life that Does Not Deserve to Live: Articulations on School
Abandonment and Black Masculinities
}

Beatriz Giugliani**

Universidade Federal da Bahia (Salvador, Brasil)

\begin{abstract}
* Trabalho alinhado com a tese de doutorado/2015 O abandono dos jovens homens negros no Ensino Médio, estudo interdisciplinar na escola pública no município de São Félix / Bahia - Brasil do Programa Multidisciplinar de Pós-Graduação em Estudos Étnicos e Africanos (Pós-Afro UFBA), defendida em agosto de 2019 cujo tema tem relação com o abandono de jovens homens negros do Ensino Médio em cidade do interior da Bahia Apoio da CAPES. Artigo de pesquisa recebido em 16.02.2019 e aceito em 29.01.2020.

${ }^{* *}$ Doutora em Estudos Étnicos e Africanos pelo Programa Multidisciplinar de Pós-graduação em Estudo Étnicos e Africanos pela Universidade Federal da Bahia (Brasil). Mestre em Ciências Sociais: Cultura, Desigualdades e Desenvolvimento pela Universidade Federal do Recôncavo da Bahia (Brasil). Especializada em Educação Psicomotora e em Pedagogia da Arte - Lato Senso, ambas pela Universidade Federal do Rio Grande do Sul (Brasil). Graduada em Licenciatura Plena em Música pela Universidade Federal do Rio Grande do Sul (Brasil).E-mail: bgiugliani@yahoo.com.br ORCID: https:// orcid.org/oooo-0o03-3032-675X
\end{abstract}




\section{Cómo citar/How to cite}

Giugliani, Beatriz (2O20). Vida que não merece viver: articulações sobre abandono escolar e masculinidades negras. Revista CS, 31, 359-383. https://doi.org/10.18046/recs.i31.3425 
O ensaio pretende analisar de forma crítico-interpretativa o fenômeno da defasagem escolar dos rapazes em relação às moças no Ensino Médio, tema no qual fatores relacionados com gênero se combinam com questões de raça e de classe. De todo modo, admitindo que são os meninos negros provenientes de camadas pobres da população as principais vítimas do fracasso escolar, a discussão da construção das masculinidades racializadas e a relação que eles estabelecem com o processo de escolarização são imperativas. $\mathrm{O}$ presente texto tem um caráter argumentativo na medida que fica restrito às intersecções entre os embates político-científicos das relações raciais e de gênero, das masculinidades negras, das relações de poder, das subjetividades e identidades masculinas racializadas, da violência de Estado, tendo como base, efetivamente, os estudos teóricos e empíricos.

\section{PALAVRAS-CHAVE:}

masculinidades negras, ensino médio, relações raciais, relações de gênero, relações de poder

El ensayo tiene la intención de analizar de forma crítica e interpretativa el fenómeno del retraso escolar de los hombres jóvenes en relación con las mujeres jóvenes en la escuela secundaria, un tema en el que los factores relacionados con género se combinan con cuestiones de raza y clase. En cualquier caso, admitiendo que los niños negros de sectores pobres de la población son las principales víctimas del fracaso escolar, la discusión sobre la construcción de masculinidades racializadas y la relación que establecen con el proceso escolar es imperativa. El presente texto tiene un carácter argumentativo en la medida en que queda restringido a las intersecciones entre los enfrentamientos político-científicos de las relaciones raciales y de género, de las masculinidades negras, de las relaciones de poder, de las subjetividades e identidades de las masculinas racializadas, de la violencia estatal, con base, efectivamente en estudios teórico-empíricos.

\section{PALABRAS CLAVE:}

masculinidades negras, escuela secundaria, relaciones raciales, relaciones de género, relaciones de poder 
The essay aims to critically-interpretatively analyze the phenomenon of school lag of boys in relation to girls in high school, a theme in which gender-related factors are combined with race and class issues. In any case, admitting that black boys from poor sections of the population are the main victims of school failure, the discussion of the construction of racialized masculinities and the relationship they establish with the schooling process is imperative. The text has an argumentative character as it is restricted to the intersections between the political-scientific clashes of racial and gender relations, of black masculinities, of power relations, of subjectivities and racialized masculine identities, of state violence; all this based, effectively, on theoretical-empirical studies.

\section{KEYWORDS:}

Black Masculinities, High School, Race Relations, Gender Relations, Power Relations 


\section{Introdução}

Segundo Suely Carneiro, o saber do negro é visto como prática discursiva de diferenciação social conforme a racialidade, "(...) que permite a distinção social de cada indivíduo por discursos de raça, produzidos no interior de relações de poder" (Carneiro, 2005: 51). Abordando questões como raça e racismos, o texto abordará a relação entre educação e desigualdade destacando as assimetrias entre brancos e negros, evidenciando, neste nosso caso específico, as assimetrias entre o aproveitamento escolar dos rapazes/meninos e das moças/meninas como apontado em dados oficiais bem como em investigações teóricas e empíricas, onde, na maior parte dos casos, são os rapazes negros os que mais desistem dos estudos e os mais retidos na série/ano escolar.

Para além do caráter argumentativo, o texto pretende explorar de forma crítico/ interpretativa de que maneira o racismo, as relações de poder e a discriminação racial estão presentes e/ou acontecem na escola - e no caso desse contexto, no interior da Bahia. O texto está alinhado à tese de doutorado $O$ abandono dos jovens homens negros no Ensino Médio, estudo interdisciplinar na escola pública no município de São Félix /Bahia - Brasil (Giugliani, 2019), defendida em agosto de 2019. A investigação privilegiou analisar a construção social das masculinidades nesse contexto, bem como os processos cotidianos que levam esses rapazes a abandonarem a escola nessa etapa de ensino.

Buscou-se ainda compreender os modos de subjetivação enquanto uma construção de novos processos numa perspectiva étnico-política, de observá-los como processos de subjetivação já como efeitos das táticas de poder, que produzem o corpo, sua submissão e repartição em condições de colonialidade de poder.

Com efeito, negritude e branquitude ${ }^{1}$ apresentam condicionantes diferenciados quanto à fazer morrer ou deixar viver. Para Foucault (2009), o racismo no campo

1. Precisaríamos destacar aqui que o debate que interroga e questiona o papel do branco nas relações raciais do mundo e em especial do Brasil é recente, tendo avançado de forma mais articular na esfera da produção acadêmica, no que se refere a experiência de desconstrução do estereótipo que mantém o negro em uma condição inferior, posto que o branco foi, por toda a história, representado e auto representado como o ser humano ideal, dotado de privilégios e legitimado pela sociedade até os nossos dias. Em suma, os estudos sobre branquitude, apesar de terem sido discutidos no início do século XX por Frantz Fanon, ganha relevância somente no ano de 1990. Importante lembrar que o autor, no seu livro Pele negra, máscaras brancas de 1952, propõe justamente um exame da relação entre o branco e o negro, demostrando como um vê o outro, a primordialidade estabelecida no negro de ser branco, e por outro lado, o branco apropriando-se da condição de único ser humano - a própria invenção de limitações a partir das identidades raciais. No Brasil, somente no ano de 2000, a pesquisadora Edith Piza apresenta publicações cujo tema da branquitude, passando a ser uma ideia marcada. A proposta, além de discutir o silenciamento do branco perante a história, como maneira de manter o status quo, serviu como estratégia 
do biopoder, na qualidade de tecnologia de poder voltada para preservar a vida de uns e abandonar a de outros, presta-se à sentença do fazer morrer ou deixar viver, que podemos chamar da própria expressão do biopoder. O autor define a função do racismo que integra o biopoder como elemento legitimador do direito de matar, intrínseco ao poder soberano, que no contexto das sociedades disciplinares será exercido pelo Estado, por ação ou omissão (Foucault, 1999).

Estudos sustentados por essa perspectiva (Carvalho, 2001; 2004; Castro, 2000; McRobbie, 1978; Rosemberg, 2001; 2002; Willis, 1977), só para citar alguns autores, têm nos dado pistas reveladoras para o entendimento desse jogo imbricado de contradições que constroem as desigualdades educacionais.

Nesse sentido, importante dar relevo ao texto original do relatório anual de 2003 do Fundo das Nações Unidas para a Infância (Unicef), de Carol Bellamy (2003), no qual a autora assinala o crescimento do fracasso escolar entre os meninos, até bem pouco tempo visto como um problema particular dos países industrializados, e hoje, uma realidade no quadro de desigualdades educacionais por gênero na América Latina e Caribe (Carvalho, 2004: 12). Mais que isso, o documento do Unicef confirma que essa "(...) desigualdade invertida de gênero não é um fenômeno simples, mas ao contrário um tema no qual fatores relacionados com o gênero se combinam com questões raciais e de classe" (Carvalho, 2004: 12). Justamente, insistimos que seria (será) impossível desconsiderar aqui as desigualdades de classe e de cor e/ou raça ao se aprofundar sobre os motivos que levam os rapazes negros a deixarem a escola.

Diante disso, optamos agora por recuar na história, mesmo que brevemente, e assinalar a década de 1980, tempo da abertura política e redemocratização da nossa sociedade. Foi nesse período que assistimos a uma nova forma de atuação política dos negros (e negras) brasileiros. Novos movimentos sociais passaram a atuar ativamente, sobretudo os de caráter identitário, trazendo outro conjunto de problematizações e novas formas de atuação e reivindicação política. Nesse período, o Movimento Negro requisita ao Estado que a questão racial deva ser compreendida como uma forma de opressão e exploração estruturante das relações sociais e econômicas brasileiras, acirrada pelo capitalismo e pela desigualdade social (Gomes, 2011:111).

para aumentar a visibilidade sobre o negro. De outra parte, Negritude, criado por Aimé Césáire em 1938, é considerado um conceito ainda com definição imprecisa, segundo a pesquisadora Lígia F. Ferreira (2006). Ela ainda aponta que Césáire em sua poesia apresenta a palavra com três sentidos distintos, como povo negro, vivência íntima do negro e como revolta. Na década de 1930, os (ainda) estudantes africanos Sédar Senghor, Aimé Césaire e Leon Damas dinamizam o conceito - mesmo na sua forma impressa - e a transformam em sinônimo de afirmação, posição política, reabilitação da identidade cultural e da personalidade própria dos povos negros. Para aprofundar mais, principalmente no que se refere ao conceito de negritude no Brasil, ver Ferreira (2006). 
De acordo com a pesquisadora Nilma Gomes (2011), a população negra se encontra, na sua grande maioria, representada de maneira precária e, por vezes, subalterna nos escalões do poder. A partir dos anos de 1980, a trajetória política do Movimento Negro mergulhada nas múltiplas “(...) mudanças vividas pela sociedade brasileira (...), se dá de forma articulada com as transformações na ordem internacional, o acirramento da globalização capitalista e a construção das lutas contra hegemônicas" (Gomes, 2011: 112).

Desigualdade e discriminação de gênero e de raça são problemas relacionados com a maioria da população. A respeito desse quadro cada vez mais evidente de desigualdade, o debate público em alguma medida se fortaleceu, reforçando iniciativas no campo das políticas de governo.

Ainda que no Brasil meninos e meninas tenham igual acesso à educação básica, em termos de matrícula e conclusão, as meninas estão melhores que os meninos (Instituto Brasileiro de Geografia e Estatística [IBGE], 2009). Além disso, a diferença a favor das meninas é ainda mais importante quando se compara taxas de distorção idade-série. Enquanto 22\% dos meninos entre 10 a 14 anos não estão matriculados na série correta, apenas $15 \%$ das meninas estão na mesma situação (IBGE, 2009). No Nordeste rural, a área mais pobre do país, juntamente com o Norte rural, Harbison e Hanushek (1992: 70) descobriram que as meninas são mais propensas do que os meninos a permanecerem na escola e serem aprovadas. Henriques (2002) também mostra que, para todos os grupos raciais, as meninas tendem a se matricular em maiores proporções e alcançar níveis mais altos de escolaridade que os meninos.

Essa vantagem das meninas reafirmada principalmente nos últimos 20 anos faz com que alguns pesquisadores visualizem esta "defasagem" a favor delas mais como um reflexo dos problemas específicos enfrentados pelos meninos no processo de escolarização do que o fato de as mulheres estarem conquistando seu lugar na sociedade por meio da educação. (Rosemberg y Carvalho, como citado em Giugliani, 2016: 6)

Nas sociedades contemporâneas, as aprendizagens sociais fazem-se em diferentes contextos - a família, a escola, a mídia, grupos de pares -, cada um com sua importância distinta a cada período da vida. No caso deste texto, ressaltamos o contexto escolar. Ele possui uma relevância na forma como instiga a construção de uma maneira específica de masculinidade e de feminilidade, principalmente na regulação do corpo e na promoção de comportamentos considerados adequados.

Esse ponto merece, entretanto, ser distinguido, ou seja, "masculinidade e feminilidade não são sobreponíveis, respectivamente, a homens e mulheres", por se tratar de "(...) metáforas de poder e de capacidade de ação como tal acessíveis a homens e mulheres", afirma Almeida (1996: 162), e continua: 
Se assim não fosse, não se poderia falar nem de várias masculinidades nem de transformações nas relações de gênero. O caráter móvel e contingente da relação entre masculinidade, homens e poder torna-se claro quando analisamos etnografias que prestam atenção ao diálogo e conflito entre masculinidades hegemônicas e subordinadas, ou que prestam atenção quer à variabilidade individual das identidades masculinas, quer às alterações destas num só indivíduo ao longo do ciclo de vida ou consoante diferentes situações de interação. (Almeida, 1996: 162)

Analisar a construção das masculinidades em contexto escolar a partir dos significados produzidos pelas próprias representações possibilita que identifiquemos os sentidos que esses jovens dão à experiência vivida, assim como os mecanismos pelos quais a cultura juvenil nesse ambiente concorre para esta construção. De acordo com Woodward, “(...) são os discursos e os sistemas de representação que constroem os lugares a partir dos quais os indivíduos podem se posicionar e a partir dos quais podem falar" (Woodward, 2009: 17).

A escola assume, assim, um papel ativo na construção de identidades, apelando a mensagens estereotipadas sobre as possibilidades disponíveis para cada sexo, ou seja, a existência de um discurso direcionado para um estudante neutro é feita em paralelo com uma intensa normalização de áreas adequadas a cada um dos sexos. Nessa perspectiva, Guacira Louro (2000: 41) reitera que “(...) a escola está absolutamente empenhada em garantir que meninos e meninas se tornem homens e mulheres que correspondam às formas hegemônicas de masculinidade e feminilidade".

A construção de masculinidades nas escolas está longe da mera aprendizagem de normas, como diz Connell (2000:164). Seguindo a autora, essa construção é um processo com diversos caminhos, tendo a classe e a etnicidade produzido múltiplos resultados. Ou dito em outros termos: a escola deve ser entendida enquanto espaço de sociabilidade e de relação entre pares, salientando o papel dos estudantes como interlocutores nos processos de construção de masculinidades. "Trata-se de uma ordem de gênero que se relaciona com as estruturas sociais mais amplas, mas possui uma dinâmica escolar própria e sempre mutável" (Carvalho, 2011: 169). Além disso, “(...) para entender o gênero devemos ir constantemente mais além do próprio gênero", diz Connell (1997: 38). Este é um importante alerta se entendemos que é sempre no encontro entre diferentes formas de subordinação e de poder que se faz “(...) possível compreender as posições, as escolhas e as identidades de meninos e rapazes, moças, mulheres e meninas" (Carvalho, 2011: 160).

Como em diferentes autores, repele-se o determinismo que dispõe os sujeitos como objetos passivos. De maneira oposta, destacamos que o sujeito resiste, negocia, interpreta, contesta os valores, códigos que estão socialmente disponíveis, concedendo-lhes um sentido e construindo uma autonarrativa para si mesmo e para 
os outros (Carrito; Araújo, 2013: 146; Carvalho, 2011; Kimmell, 1997). As formas de organização das masculinidades nas escolas são cambiantes e os estudantes se envolvem "(...) simplesmente entrando na escola e vivendo em suas estruturas" (Carvalho, 2011: 168), negociando, ajustando-se aos padrões, revoltando-se contra esses ou buscando mudá-los, como revela Connell (2000: 154). Sobretudo, no que tange à disciplina,

(...) onde a hegemonia da escola é segura, os meninos podem aprender a manejar o poder disciplinar por si mesmos como parte de seu aprendizado da hierarquia masculina (...) quando a hegemonia é falha, uma masculinidade de protesto pode ser construída por meio do desafio à autoridade, muito familiar nas escolas de classe trabalhadora. (Connell, 2000: 159)

Por isso, e por óbvio, sobrevém a preocupação compulsória em desmontar noções de homem enquanto identidade única, a-histórica e essencialista, para pensar masculinidade como diversidade no bojo da historicidade de suas inter-relações, “(...) rastreando-a como múltipla, mutante e diferenciada no plano das configurações" (Matos, 2001: 47) de regulações, práticas, subjetivações e representações.

Nos estudos de homens e suas masculinidades, em especial, nas suas relações de gênero no contexto escolar, em termos teóricos e metodológicos, buscamos uma reflexão crítica e antirracista. Por muito tempo, ao longo da história da América Latina, a ideologia da mestiçagem - da mescla de três raças na América Latina, composta de povos espanhóis [portugueses]/indígenas/negros -, referenciava um homem genérico, sintetizado magicamente como um todo mestiço, um homem mestiço único (Viveros-Vigoya; Gutmann, 2007: 121). Apenas nos últimos anos do século passado é que os estudos centrados nas masculinidades de homens negros começaram a circular na região latino-americana.

Desde a conquista da nossa América, trabalho, raça e gênero se articulam como os três eixos principais de classificação social do novo padrão mundial de poder, diz Quijano (2005). As diferenças fenotípicas, como a cor da pele, a forma e cor do cabelo, dos olhos, do nariz, começam a ser utilizadas no processo de colonização como forma de diferenciar conquistadores e conquistados, europeus e não europeus, estabelecendo, assim, uma relação de superioridade e inferioridade pautada nas distintas estruturas biológicas de cada grupo social e criando supostas gradações de seres humanos.

No contexto da América Latina, o espaço político consentido aos problemas de raça e racismo foi relevante no momento de configurar “(...) as novas nações que tiveram de lidar de distintas formas com o dilema colocado pela composição racial de suas populações - visivelmente mescladas - e o desejo e a vontade de acessar as 
vantagens" (Viveros-Vigoya; Lesmes, 2014:14) do avanço e da civilização inerentes às nações modernas.

Raza, etnia y nación en Mariátegui é uma publicação na qual o sociólogo Aníbal Quijano (1995) explora com bastante exatidão o tema da raça. Define-a como uma ideia, uma construção ideológica, um fato social total, um acontecimento, uma invenção sem a qual a modernidade não poderia ter existido, um instrumento de dominação social, introduzido há mais de 500 anos e que permanece até hoje virtualmente intocado (Walsh, 2010: 98).

Mesmo planejando e adotando medidas específicas de políticas públicas nos últimos anos, os cálculos que têm sido realizados revelam indicadores das taxas de escolarização distorção idade-série, ainda muito inadequadas. Em estudos analíticos como os de Marília Carvalho (2001) e Fúlvia Rosemberg (2001), a evidência se repete: na realidade educacional brasileira, a escolarização dos rapazes apresenta piores indicadores que das meninas. Se considerarmos, por exemplo, somente o Gráfico 1 veremos um real aumento entre os anos observados de todos os grupos. O sistema educacional brasileiro expandiu-se de forma significativa nos últimos anos, revelando, entre outros, a elevação da escolaridade média da população e o aumento do número de matrículas em todos os níveis de ensino.

Entretanto, o peso dos níveis de mais baixa escolaridade é maior entre os negros do que entre os brancos. A incorporação do recorte de gênero não altera a estrutura da distribuição da escolaridade da população brasileira a partir do recorte racial, ou seja, as mulheres negras também permanecem com índices abaixo dos homens brancos, ressaltando que a raça reforça a manutenção da desigualdade educacional. Ou seja, podemos observar, um grande contraste, se levarmos em consideração o gênero e a classificação racial, por exemplo, entre as mulheres brancas e as mulheres negras, e entre estas últimas e os homens brancos. Maiores ainda são as distâncias se considerados os homens negros em relação aos outros grupos de cor e sexo, como o Gráfico 1 demonstra claramente.

A assimetria entre homens e mulheres, e negros e brancos, já foi bastante analisada por diferentes pesquisadores, e continua apontando um persistente desequilíbrio entre os grupos. Por exemplo, a taxa das mulheres brancas que no ano de 1995 era maior 27 pontos percentuais em relação a dos homens negros, em 2015-portanto, 20 anos depois -, regrediu muito pouco em relação a esse mesmo segmento, somente 22 pontos percentuais, o que pode representar, um verdadeiro desafio histórico para qualquer sociedade contemporânea.

Destarte, percebe-se um crescimento significativo das taxas de escolarização das mulheres negras nessa etapa de ensino, em 2015 elas atingiram 57 pontos percentuais, chegando muito próximo dos homens brancos, com 59 pontos percentuais. 

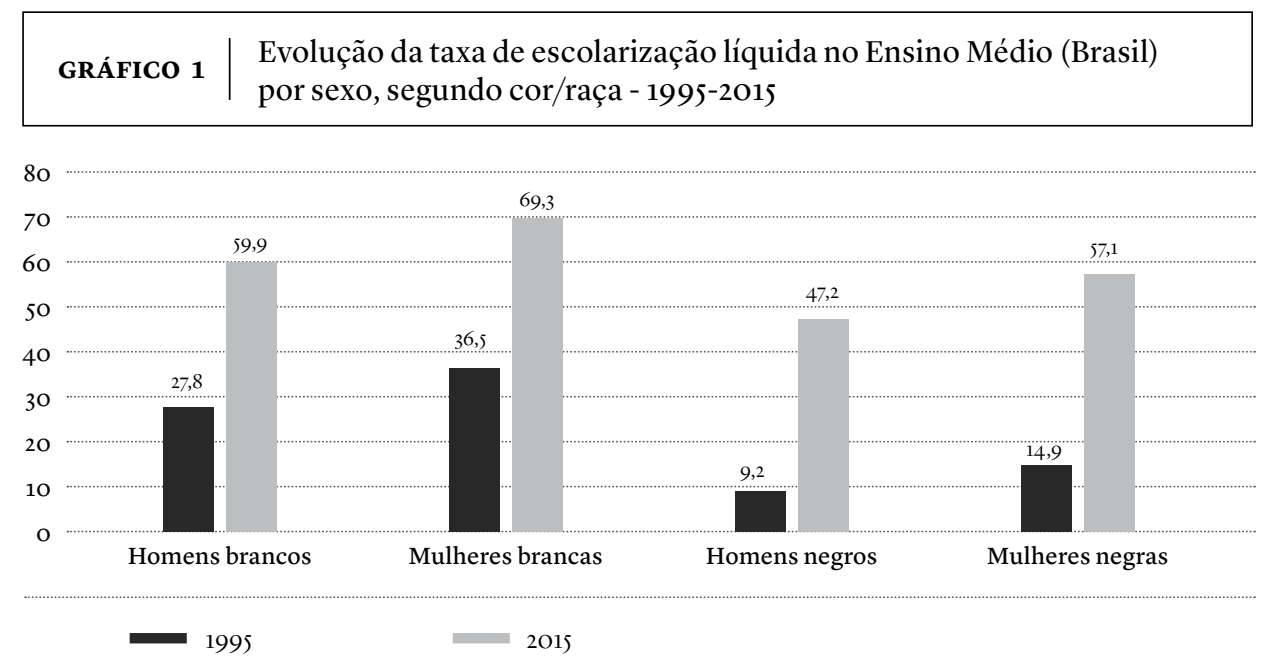

Fonte: IBGE/PNAD. Elaboração: IPEA/DISOC. Dos 17 anos mostrados na tabela original, selecionamos apenas dois (1995 e 2015) para esse nosso caso específico, transformando-os no formato de gráfico.

\section{Desigualdades educacionais entre brancos e negros: raça e gênero}

Estudos revelam que o fracasso escolar está relacionado não só à origem racial, mas também ao sexo dos estudantes, à sua origem familiar e à região onde mora (Alves; Ortigão; Franco, 2007; Louzano, 2004; 2013). Da mesma forma, Carlos Hasenbalg e Nelson Vale Silva (1999), mostram as desigualdades educacionais entre brancos e negros como algo produzido tanto pela estrutura familiar, pela região de domicílio, pela escolaridade dos pais, quanto pela própria estrutura do sistema de ensino. Melhor dizendo, preconceitos de raça e de classe e seus estereótipos consistem em uma cultura apoiada na ausência de diálogo e no abuso das relações de poder entre estudantes e adultos da escola, por exemplo. Nesse sentido, Maria Helena Patto (2009) denuncia justamente o que ocorre na maior parte dos pareceres e laudos psicológicos endossados pelo poder da própria instituição escolar, ou seja, a maioria deles:

(...) nada mais faz do que dar credibilidade a preconceitos de raça e de classe, mesmo quando esses pareceres se valem de concepções caducas no campo das ciências humanas (por exemplo, a crença no primitivismo dos não brancos) e de estereótipos verbais trazidos pela recente epidemia de livros de autoajuda (a psique humana reduzida a autoestima). E a credibilidade vem da condição do especialista, alçado à condição de 
único competente para dizer. É assim que a maioria dos laudos confirma queixas leigas e afirma o que os solicitantes dos exames psicológicos querem ouvir. Ao agirem assim no âmbito escolar, os profissionais da psicologia cometem pequenos assassinatos, quando minam a identidade do culpado, e crimes de lesa-cidadania, quando justificam a negação do direito à educação escolar. (Patto, 2009: 408)

A preponderância de visões e silenciamentos da vida real que recorrem a estratégias como os laudos psicológicos referidos acima, desconsideram, evidentemente, a complexidade dos homens como seres sociais historicamente construídos, tornando-se eles próprios - os psicólogos -, "reduzidos a coisas: tornam-se máquinas de gestão de riscos sociais, exercem a função de cães de guarda do sistema" (Patto, 2009:408).

Fica claro que tudo isso contribui para configurar mentalidades etnocêntricas, essas que tendem a explicar tudo a partir de dicotomias exclusivas entre o bom e o mau. Para Santomé (2013:164-165) "esta é uma das maneiras de construir e reforçar estereótipos e preconceitos sobre grupos e povos marginalizados e sem poder e, por conseguinte, de lhes atribuir responsabilidades exclusivas pelas situações que lhes são impostas".

De outro modo, e também atenta a essa realidade, a pesquisadora Marília de Carvalho (2009) evidencia:

Interações entre sexo e a cor da pele na construção de sofríveis resultados entre meninos pretos ou pardos. Seus estudos realizados por uma década deixam transparecer que aspectos fenótipos relacionados à cor preta são frequentemente associados pelos professores à pobreza e ao baixo desempenho dos estudantes. São estatísticas nacionais que persistem indicando de maneira evidente a diferença de desempenho escolar entre meninos/rapazes e meninas/moças, e que os maiores problemas se referem ao grupo de alunos negros do sexo masculino. (Carvalho, como citado em Giugliani, 2016: 7)

Importaria igualmente considerar, outrossim, as desigualdades sociais, raciais e de gênero e de classe não somente como fruto da discriminação do passado, mas também como um processo ativo de preconceitos e estereótipos que legitimam permanentemente a exclusão dos negros no Brasil.

\section{Raça, masculinidade e poder}

Para Welzer-Lang (2001: 461) ser homem é uma aprendizagem ao longo da vida, como um ideal que se segue com a "submissão ao modelo e obtenção dos privilégios do modelo". Como disse em outro lugar: 
O modelo, por meio de práticas incessantemente reproduzidas, assegura que o poder é exercido por certo tipo de homens que possuem privilégios e ascendência sobre outros grupos masculinos e sobre as mulheres. Ao falar de "modelo" relacionamos com as contribuições de Connell (2001) para o conhecimento da(s) masculinidade(s) no campo sociológico. Ela defende a existência de diferentes formas de ser homem que são históricas, social e culturalmente construídas, [isto é], a masculinidade é a forma como cada sociedade interpreta e usa os corpos masculinos (e também femininos). A autora introduz ainda o conceito de masculinidade hegemônica, definida como referência-modelo. Esta masculinidade de referência tem sustentado, ao longo dos tempos, a dominação masculina, ocupando uma posição dominante em determinado tempo e lugar. (Giugliani, 2016: 8)

\section{Ou como coloca Kimmell:}

La definición hegemónica de la virilidad es un hombre en el poder, un hombre con poder, y un hombre de poder. Igualamos la masculinidad con ser fuerte, exitoso, capaz, confiable, y ostentando control. Las propias definiciones de virilidad que hemos desarrollado en nuestra cultura perpetúan el poder que unos hombres tienen sobre otros, y que los hombres tienen sobre las mujeres. (Kimmel, 1997:3)

Tal como esclarece Souza (2010: 113-114), a masculinidade é um composto de particularidades que dão sentido ao masculino e que, sincronicamente, ajuda a demarcar a diferença do feminino, constitui uma "posição nas relações de gênero que influencia as práticas e a forma como o sujeito se relaciona com experiências físicas, pessoais e culturais" (Souza, 2010: 113). O que vai desfazer o dualismo - a princípio inevitável - do feminino/masculino é a noção da masculinidade hegemônica, ou essa variedade particular de masculinidade que subordina outras variedades (Almeida, 2000: 149).

Se a fissura entre as categorias de homem e mulher é um dos fatos centrais do poder patriarcal e da sua dinâmica,

no caso dos homens, a divisão crucial é entre masculinidade hegemônica e várias masculinidades subordinadas. Daqui, segue-se que as masculinidades são construídas não só pelas relações de poder, mas também pela sua inter-relação com a divisão do trabalho e com os padrões de ligação emocional. Por isso, na empiria, se verifica que a forma culturalmente exaltada de masculinidade só corresponde às características de um pequeno número de homens. (Almeida, 2000: 149-150)

O debate sobre as identidades e as práticas sexuais e de gênero, na verdade, desde os anos sessenta, vem se tornando cada vez mais vivo principalmente provocado 
pelo movimento feminista que, sem dúvida teve a função de redefinir as identidades sociais, tornando-as visiveis e causando, em seu transcurso de afirmação e diferenciação, novas divisões e, também, o surgimento do que chamamos agora de políticas de identidades (Hall, 2002).

Importante chamar a atenção que, além do movimento feminista, os movimentos pelas liberdades sexuais e direitos humanos de gays e lésbicas, provocaram "uma desconstrução ou desnaturalização da mulher como entidade móvel, ou melhor, imobilizada pelo peso do patriarcalismo, das convenções e das estruturas sociais opressivas" (Pinho, 2004: 65). O efeito evidente e político desse processo, segue o autor, revelaria que não somente a mulher foi "desenhada pela pena do poder e da dominação masculina", mas o próprio homem percebeu-se surpreendido ao ver que era, do mesmo modo, "um artefato das estruturas de gênero" (Pinho, 2004: 65).

\begin{abstract}
De um jeito ou de outro, principalmente no campo da psicologia e da antropologia social, começou a se apresentar uma relativização histórica da figura masculina, até então entronizada e vendida como monolítica, imutável, essencial, eterna e, eventualmente, divina ou metafísica. O homem foi reconduzido à sua diversidade e variação histórica. Aprendeu a perceber que existem muitas formas diferentes de masculinidades que se multiplicam pela história e pelas culturas. Também aprendeu a perceber as diferentes versões de masculinidades correntes, ou mais ou menos coabitantes, no ambiente sociocultural das sociedades modernas. Algumas dessas versões são identificadas com as estruturas sociais dominantes, algumas apenas parcialmente e outras francamente subordinadas às estruturas e representações dominantes sobre o masculino ou delas marginalizadas. Nesse caso, seria possivel falar de masculinidades hegemônicas ou hegemonizadas e em subalternas ou subalternizadas. (Pinho, 2004: 65)
\end{abstract}

Mas então: "quem é o sujeito de direito?" (Mbembe, 2011:20). Seguindo a noção de Foucault de biopoder, Mbembe configura a segregação de pessoas - as que devem morrer e as que devem viver - como um poder que se limita ao campo biológico. Um controle que implica o ordenamento da espécie humana em grupos distintos e a instalação de uma suspensão biológica entre os indivíduos - falamos do racismo (Mbembe, 2011: 21-22).

Ao afirmar que o Estado ocidental moderno utilizou numa proporção sem precedentes, tecnologias de individualização, subjetivação e procedimentos de totalização, Foucault (2014) apresenta três modelos de exercício de poder: o disciplinar, o biopoder e o da soberania. Tais poderes não se excluem, eles se complementam; ao passo que as técnicas disciplinares, por exemplo, são construídas no âmbito da soberania como forma de sujeitar o corpo do indivíduo - tornando-o dócil, manipulável. 
Na teoria clássica da soberania, o direito de vida e de morte era um de seus atributos fundamentais. Ora, o direito de vida e de morte é um direito que é estranho, estranho já no nível teórico; com efeito, o que é ter direito de vida e morte? Em certo sentido dizer que o soberano tem direito de vida e morte significa, no fundo, que ele pode fazer morrer e deixar viver; em todo caso, que a vida e a morte não são desses fenômenos naturais, imediatos, de certo modo originais ou radicais, que se localizariam fora do campo do poder político (Foucault, 1999: 286).

Mais que isso, o terror moderno deve levar em conta outras questões como a dominação, a emancipação e a escravidão, essa última considerada como uma das primeiras manifestações da experimentação biopolítica (Mbembe, 2017: 130). Não poderemos nos expandir muito mais nesse espaço, portanto, por todas as razões anteriormente descritas, diríamos com Mbembe (2017: 132) que:

A vida do escravo é, em certos aspectos, uma forma de morte-na-vida, se estabelece uma relação desigual uma vez que se afirma desigualdade do poder sobre a vida - a humanidade de uma pessoa se dissolve até o ponto que é possível afirmar que a vida de um escravo é propriedade de seu amo. Dado que a vida do escravo é uma "coisa" possuída por outra pessoa, a existência do escravo é a sombra personificada.

O colonizado é reduzido ao estatuto de Negro, entendido como o Outro: o específico, sempre contraposto ao europeu afirmado como expressão do ser humano universal. O branco, a cultura branca, ou ocidental, ganham status de universalidade e não precisam ser especificadas. Grosfoguel (2012: 93), ao definir o racismo fanoniano, diz: "é uma hierarquia global de superioridade e inferioridade sobre a linha do humano que tem sido politicamente produzida e reproduzida como estrutura de dominação durante séculos por um sistema imperialista/ocidentalocêntrico/cristianocêntrico/capitalista/patriarcal/ moderno/ colonial" (Grosfoguel, 2012: 93).

Ao estabelecer a linha do humano, isso é, a espacialização da ocupação colonial, Frantz Fanon parece estar articulando "as expressões existenciais da colonialidade em relação com a experiência racial" (Maldonado-Torres, 2007:130). A classificação dos indivíduos a partir do reconhecimento ou não reconhecimento social em sua humanidade significa o limite dos humanos e dos sub-humanos ou não humanos. Em Pele negra, máscaras brancas, Fanon (2008) inicia o seu processo para traçar, segundo Maldonado-Torres (2007: 130), o que se pode tomar como o "aparato existencial do sujeito produzido pela colonialidade do ser".

Ora, se é verdade que, no mundo capitalista/colonial/imperialista, a linha divisória transversal traspassa e ordena as relações de opressão de classe, sexualidade 
e gênero, então é possível visualizar duas zonas demarcando a zona do ser e a zona do não-ser. Racializados como seres superiores, os primeiros não vivem a opressão, ao contrário, experimentam o privilégio racial. Por outro lado, na zona do não-ser, sujeitos racializados como inferiores, experimentam a opressão e não conhecem situações de privilégio racial (Grosfoguel, 2012: 95).

\section{O homem negro no contexto brasileiro}

No livro As cores da masculinidade: experiências interseccionais e práticas de poder na Nossa América, a pesquisadora colombiana Mara Viveiros-Vigoya apresenta uma perspectiva pós-colonial muito particular sobre homens, masculinidades, gênero e colonialidade, posicionando seu trabalho em outra tradição de pensamento: o mundo colonial e pós-colonial fora da metrópole global da Europa e da América do Norte. Sua análise, por exemplo, sobre a encarnação das masculinidades negras e a presença física da raça nos coloca em um contexto social e político de vulnerabilidade que podem ser estendidas, de todo modo, à realidade brasileira. Assim, como coloca a autora (Viveiros-Vigoya, 2018: 183), "falar de 'homens' faz sentido se isso permite evidenciar as continuidades entre certas práticas educativas e normas de socialização transmitidas aos homens, e o uso de armas, o exercício da violência, o desempenho masculino agressivo e frequentemente misógino". Ainda faz questão de destacar que a compreensão de gênero como uma estrutura que abrange tanto a personalidade e a cultura quanto a experiência corporal, explicaria que podemos associar masculinidades e violência. De outro lado, devemos, seguindo a autora, compreender o gênero (e no gênero, a masculinidade) como um efeito histórico e uma prática produtora de história. Gênero e sexualidade são sempre provocados em processos de grande violência como a colonização, a conquista e a "construção de nações na nossa América" (Viveiros-Vigoya, 2018:183).

O homem negro é representado (hiper-representado) como um corpo, um corpo negro, e concebido racialmente com uma conjuntura provocante dessas representações que agem como estruturas de apoio para "práticas concretas de exclusão, marginalização e violência" (Pinho, 2004: 66).

Essa conjuntura estrutural que viabiliza as "práticas de exclusão, marginalização e violência" aponta, efetivamente, para as desigualdades de gênero na escolarização que têm favorecido as mulheres, como vimos no início desse texto, desde as últimas décadas do século XX (Rosemberg; Madsen, 2011). São os meninos/rapazes que evidenciam maiores taxas de reprovação e evasão, nem tampouco de conclusão dos ensinos fundamental e médio. Contudo, dado o que foi apresentado acima, é 
mais do que preciso investigar e analisar o contexto sociocultural e socioestrutural que produz e mantém tais disparidades. Nesse âmbito, talvez o movimento a fazer seja levantar a seguinte questão: "quem são os meninos [rapazes] que fracassam na escola?” (Rezende; Carvalho, 2012).

Se reconhecemos que são os meninos negros provenientes de camadas pobres da população as principais vítimas do fracasso escolar, a discussão da construção das masculinidades racializadas e a relação que eles estabelecem com o processo de escolarização fazem-se urgentes. Ou mais especificamente, de que maneira o racismo, as relações de poder e a discriminação racial estão presentes e/ou acontecem na escola - e no caso desse contexto, no interior da Bahia.

Em outros estudos, como no caso da investigação dos pesquisadores Paulo Melgaço da Silva Junior, Marcio Caetano e Treyce Goulart (2016), se buscou questionar os modos como as masculinidades hegemônicas de duas escolas públicas da região da Baixada Fluminense do Rio de Janeiro interagem com as identidades sexuais dissidentes, a exemplo de gays, travestis e transexuais, do mesmo modo que estão atravessadas pelas expectativas em torno da(s) masculinidade(s) negra(s) (Melgaço; Caetano; Goulart, 2016: 214). Como afirma um dos autores, sexo consiste em uma questão política na qual as sociedades utilizam para sistematizar culturalmente os sujeitos nos jogos identitários (Caetano, 2011). Ora, uma sociedade normalizadora é, evidentemente, consequência de uma tecnologia de poder centralizada na vida (Moita Lopes, 2002). Códigos, normas, dispositivos, regras são empregados "de forma sutil, de modo que tornam aceitável um poder essencialmente normatizador" (Melgaço et al., 2016: 218).

A questão da identidade tem uma posição central e fundamental, e "foi estabelecida, na América Latina desde a violenta destruição das sociedades/culturas aborígenes pelos invasores europeus" (Quijano, 1992: 74). Por cima dos destroços dessas culturas, e sobre os sobreviventes, eles estabeleceram “(...) sua dominação colonial, e foi dessa matriz que surgiu uma nova sociedade colonial” (Quijano, 1992: 74); logo depois, independentes politicamente, “(...) sem que isso implicasse semelhante descolonização das relações de poder dessa sociedade" (Quijano, 1992: 74). Portanto, a colonialidade do poder se refere à implantação de um sistema de classificação social fundada na hierarquia racial e sexual, “(...) na formação e distribuição de identidades sociais do superior ao inferior: brancos, mestiços, índios, negros", como revela Walsh (2008: 137).

Este es el uso de «raza» como patrón de poder conflictivo y permanente que desde la colonia hasta hoy ha mantenido una escala de identidades sociales con el blanco masculino en la cima y los indios y negros en los peldaños finales, éstas últimas como 
identidades homogéneas y negativas. Este patrón de poder ha servido los intereses tanto de la dominación social como de la explotación del trabajo bajo la hegemonía del capital; por tanto, «la “racialización” y la “capitalistización” de las relaciones sociales de tal nuevo patrón de poder, y el "eurocentramiento" de su control, están en la base misma de nuestros actuales problemas de identidad», como país, «nación» y Estado. (Walsh, 2008: 137)

\section{Violência e poder: palavras finais}

Já vem sido falado em diversos meios que os homicídios no nosso país - tanto quem mata, quanto quem morre - tem cor/raça. Julio Waiselfisz (2012), em seu Mapa da Violência, não poderia ter sido mais preciso ao afirmar que as estatísticas indicam uma epidemia de morte de jovens negros e pobres. Contudo, diz o antropólogo Osmundo Pinho (2014: 2), o panorama parece ser mais intrincado evidenciando uma forte relação "com a própria natureza do Estado e da modernidade na periferia global".

As mortes provocadas pela polícia são usualmente enquadradas como autos e resistência, uma figura jurídica que visa proteger os policiais, que no exercício da função, agem em legítima defesa, e que matem alguém na linguagem jurídico-policial um opositor que, contra o policial ou sua ação, levantou injusta agressão. A morte desse sujeito matável ocorre fora do registro dos homicídios ou de crimes, e não chegam sequer a gerar nenhum tipo de processo. Sendo assim, essas mortes ocorrem, com exclusão de ilicitude. Não configuram crime algum (Pinho, 2014: 2).

No Gráfico 2 observa-se que a proporção de homicídios de jovens, desde 2002, sempre teve o conjunto de negros como o grupo mais vitimado.

Contudo, o que chama a atenção é: enquanto o número de homicídios de jovens brancos cai 33\%, o número de homicídios de jovens negros cresceu 23, 4\% de 2002 até 2010. Matam-se mais jovens negros e menos jovens brancos a cada ano no Brasil. Enquanto a taxa de homicídio de brancos cresce, no intervalo dos 12 aos 21 anos de idade, 29 vezes, com a população negra o crescimento é de 46 vezes: para cada 100 mil habitantes, morrem 2,o negros de 12 anos de idade, contra 89,6 negros de 21 anos. O Gráfico 3 ilustra essa concentração de mortes na juventude.

Um retrato inaceitável como esse nos demonstra que, além de ostentarmos índices de homicídios análogos aos de países em situação de conflito armado, "assume a realidade de uma cartografia mortal, [e] configura, efetivamente, um genocídio de base racial" (Vargas, 2010). Como argumenta Waiselfisz (2012), o motor da vitimização de negros tem sido principalmente a queda dos homicídios brancos, o que pode derivar do acesso diferenciado da população branca a estratégias e políticas de segurança. 

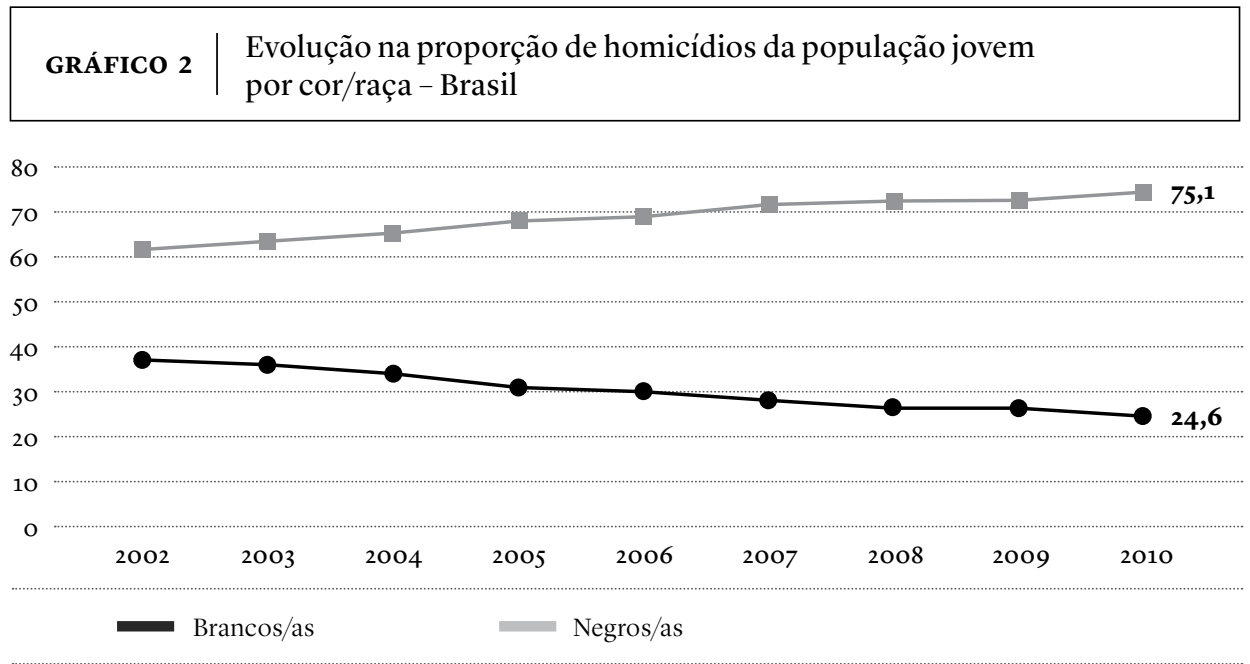

Fonte: Mapa da Violência de Waiselfisz (2012). Proporção de homicídios, no Brasil, da população jovem por cor/raça. Uma disparidade inicial entre brancos e negros vai sendo acentuada ao longo dos anos.

\begin{tabular}{l|l} 
GRÁFICO 3 & Taxas de homicídio total (em 100 mil) por idades simples
\end{tabular} e cor - Brasil. 2010

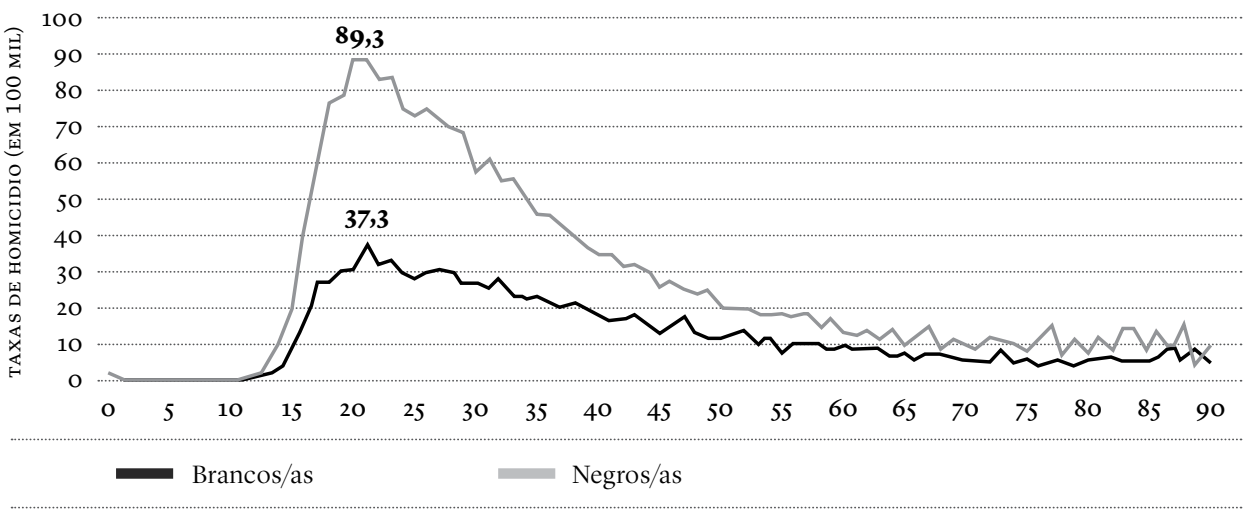

Fonte: Processamento dos microdados do SIM/SVS/MS e do Censo 2010/IBGE. Mapa da Violência de Waiselfisz (2012). Vê-se o pico em torno dos 20/21 anos, em especial para negros.

Voltamos ao título deste ensaio [Vida que não merece viver]. Quando Agamben (2010: 132) reafirma tal sentença, talvez deseje sublinhar que a sistêmica violência experimentada pela população negra parece não se configurar como crime, é algo semelhante à vida matável e insacrificável do homo sacer. 
Ou, na voz do antropólogo João Vargas:

No campo semântico planetário, as pessoas negras ocupam uma posição única e incomunicável porque a escravidão póstuma faz com que elas convivam com a violência estrutural e gratuita continuamente. Trata-se de uma violência estrutural porque, de acordo com a perspectiva de Fanon, a pessoa negra está posicionada fora dos âmbitos da sociedade civil e da Humanidade. E a violência antinegra é gratuita porque, ao contrário do que o não-negro vivencia, a violência não depende de a pessoa negra transgredir a hegemonia da sociedade civil. Ou seja, negros vivenciam violência não por causa do que fazem, mas por causa de quem são, ou melhor, de quem não são. A violência gratuita equivale a um estado de terror que é independente de leis, direitos e cidadania. A violência gratuita é terror porque é imprevisível na sua previsibilidade, ou previsivel na sua imprevisibilidade. Da perspectiva de uma pessoa negra, não se trata de perguntar se ela será brutalizada a esmo, mas quando. (Vargas, 2017: 93)

Assim, o sujeito negro habita a zona do não-ser (Fanon, 2008: 26), uma zona na qual a negação desse sujeito é igualmente "(...) a afirmação da nação com uma comunidade (branca) imaginada" (Amparo-Alves, 2016: 61). "Qual o lugar histórico dos negros e negras no projeto nacional"? - perguntamos junto com o autor. Ou ainda, seria a educação um escudo contra o genocídio negro, contra a ratificação da descartabilidade do sujeito negro?

\section{Referências}

Agamben, Giorgio (2010). Homo Sacer: O Poder Soberano e a Vida Nua I. Belo Horizonte: UFMG.

Almeida, Miguel Vale de (1996). Gênero, masculinidade e poder: revendo um caso do Sul de Portugal. Anuário Antropológico, 95, 161-19o. Recuperado de http://miguelvaledealmeida. net/wp-content/uploads/2008/o6/genero-masculinidade-e-poder.pdf

Almeida, Miguel Vale de (2000). Senhores de si: uma interpretação antropológica da masculinidade. Lisboa: Fim do Século.

Alves, Fátima; Ortigão, Isabel; Franco, Creso (2007). Origem social e risco de repetência: interação raça-capital econômico. Cadernos de Pesquisa, 37(130), 161-18o. https://dx.doi. org/10.1590/So100-15742007000100008

Amparo-Alves, Jaime (2016). Inimigo público - a imaginação branca, o terror racial e a construção da masculinidade negra em "Cidade de Deus". Em Antinegritude: o impossível sujeito negro na formação social brasileira (pp. 59-80). Cruz das Almas: EDUFRB/ Belo Horizonte: Fino Traço. 
Bellamy, Carol (2003). Estado mundial de la infancia 2004. Nueva York: Unicef. Recuperado de https://www.unicef.org/spanish/sowc/archive/SPANISH/Estado\%2OMundial\%2Ode\%2O la\%2oInfancia\%202004.pdf

Caetano, Márcio (2011). Gênero e sexualidade: um encontro político com as epistemologias de vida e os movimentos curriculares [Tese de doutorado]. Universidade Federal Fluminense do Rio de Janeiro, Rio de Janeiro.

Carneiro, Suely (2005). A construção do outro como não-ser como fundamento do ser [Tese de doutorado]. Universidade de São Paulo, São Paulo. Recuperado de https://negrasoulblog.files.wordpress.com/2016/o4/a-construcza7c3a3o-do-outro-como-ncza3o-ser-como-fundamento-do-ser-sueli-carneiro-tese1.pdf

Carrito, Manuela; Araújo, Helena (2013). A "palavra” aos jovens: a construção de masculinidades em contexto escolar. Educação, Sociedade \& Culturas, 39, 139-158. Recuperado de https://www.fpce.up.pt/ciie/sites/default/files/ESC39_M_Carrito_H_Araujo_abstracts.pdf

Carvalho, Marília (2001). Estatísticas de desempenho escolar: o lado avesso. Educação e Sociedade, 22(77), 231-252. https://dx.doi.org/10.1590/So101-73302001000400011

Carvalho, Marília (2004). Quem são os meninos que fracassam na escola? Cadernos de Pesquisa, 34(21), 77-96. Recuperado de http://www.diversidadeducainfantil.org.br/PDF/QUEM\%2O S\%C3\%83O\%2OOS\%2OMENINOS\%2OQUE\%2OFRACASSAM\%2ONA\%2OESCOLA\%2O -\%2oMarilia\%2oPinto\%2ode\%2oCarvalho.pdf

Carvalho, Marília (2009). Avaliação escolar, gênero e raça. Campinas: Papirus.

Carvalho, Marília (2011). O Conceito de gênero: uma leitura com base nos trabalhos do GT Sociologia da Educação da ANPED (1999-2009). Revista Brasileira de Educação, 19(46), 99-110. https://dx.doi.org/10.1590/S1413-24782011000100oo6

Castro, Maria Helena Guimarães de (2000). Sistemas nacionais de avaliação e de informações educacionais. São Paulo em Perspectiva, 14(1), 121-128. https://dx.doi.org/10.159o/So10288392000000100014

Connell, Raewyn (1997). La organización social de la masculinidad.Em Masculinidad/es:poder y crisis (pp.31-48), editado por Teresa Valdés; José Olavarría. Santiago de Chile: Ísis Internacional. Recuperado de http://joseolavarria.cl/wp-content/uploads/downloads/2014/o8/ Masculinidad-poder-y-crisis-Valdes-y-Olavarria.pdf

Connell, Raewyn (2000). The Men and the Boys. Berkeley: University of California Press.

Fanon, Frantz (2008). Pele negra, máscaras brancas. Salvador: EDUFBA.

Ferreira, Lígia Fonseca (2006). "Negritude", "Negridade" e "Negrícia”: história e sentidos de três conceitos viajantes. Via Atlântica (USP), 9, 163-184. Recuperado de http://www. revistas.usp.br/viaatlantica/issue/view/419o 
Foucault, Michel (1999). Em defesa da sociedade: curso dado no Collège de France (1975-1976). São Paulo: Martins Fontes.

Foucault, Michel (2009). O sujeito e o poder. Em Michel Foucault: uma trajetória filosófica para além do estruturalismo e da hermenêutica (pp. 231-249), editado por Hubert Dreyfus; Paul Rabinow. Rio de Janeiro: Forense Universitária. Recuperado de http://www.uesb.br/ eventos/pensarcomfoucault/leituras/o-sujeito-e-o-poder.pdf

Foucault, Michel (2014). História da sexualidade I: a vontade de saber. São Paulo: Paz e Terra.

Giugliani, Beatriz (outubro, 2016). Relações de gênero, masculinidades e feminilidades no cotidiano escolar: uma teia de sentidos e significados. Trabalho apresentado em III CONEDU - Congresso Nacional de Educação, CEMEP/UFPB, Natal, Brasil. Recuperado de https://editorarealize.com.br/revistas/conedu/trabalhos/TRABALHO_EVo56_MD1_SA11_ ID5297_20062016122011.pdf

Giugliani, Beatriz (2019). O abandono dos jovens homens negros no Ensino Médio: um estudo interdisciplinar na escola pública no município de São Félix, Bahia [Tese de doutorado]. Universidade Federal da Bahia, Salvador. Recuperado de https://www.academia. edu/40885900/O_ABANDONO_DOS_JOVENS_HOMENS_NEGROS_NO_ENSINO_MEDIO_Tese_de_Doutorado20191109_127399_txjv15

Gomes, Nilma Lino (2011). Diversidade étnico-racial, inclusão e equidade na educação brasileira: desafios, políticas e práticas. Revista Brasileira de Política e Administração da Educação, 27(1), 109-121. https://doi.org/10.21573/vol27n12011.19971

Grosfoguel, Rámon (2012). El concepto de "racismo" de Michel Foucault y Frantz Fanon: teorizar desde la zona del ser o desde la zona del no-ser. Tabula Rasa, 16, 79-102.

Hall, Stuart (2002). A identidade cultural na pós-modernidade. Rio de Janeiro: DP\&A.

Harbison, Ralf; Hanushek, Eric (1992). Educational Performance of the Poor: Lessons from Rural Brazil. Washington, DC: World Bank.

Hasenbalg, Carlos; Silva, Nelson do Vale (1999). Família, cor e acesso à escola no Brasil. Em Cor e estratificação social (pp. 126-147), editado por Carlos Hasenbalg; Nelson Silva; Marcia Lima. Rio de Janeiro: Contra Capa.

Henriques, Ricardo (2002). Raça e gênero nos sistemas de ensino: os limites das políticas universalistas de educação. Brasília: Unesco.

Instituto Brasileiro de Geografia e Estatística (IGBE) (2009). Síntese de Indicadores Sociais 2003. Brasília: Ministério do Planejamento.

Kimmell, Michael (1997). Homofobia, temor, vergüenza y silencio en la identidad masculina. Em Masculinidade/s: poder y crisis (pp. 49-62), editado por Teresa Valdés; José Olavarría. Santiago de Chile: Isis Internacional. Recuperado de https://www.caladona.org/grups/ 
uploads/2008/o1/homofobia-temor-verguenza-y-silencio-en-la-identidad-masculina-michael-s-kimmel.pdf

Louro, Guacira (200o). Corpo, gênero e sexualidade. Porto: Porto Editora.

Louzano, Paula (2004). Racial Inequalities in Brazilian Primary Education: How Fracasso Escolar and Race Interrelate with Student's Gender, Family Background, and Region of Residence. Qualifying Paper. Harvard University.

Louzano, Paula (2013). Fracasso escolar: evolução das oportunidades educacionais de estudantes de diferentes grupos raciais. Cadernos Cenpec, 3(1), 111-133. http://dx.doi.org/10.18676/ cadernoscenpec.v3i1.205

Maldonado-Torres, Nelson (2007). Sobre la colonialidad del ser: contribuciones al desarrollo de un concepto. Em El giro descolonial: reflexiones para una diversidad epistémica más allá del capitalismo global (pp. 127-168), editado por Santiago Castro-Gómez; Ramón Grosfoguel. Bogotá: Siglo del Hombre.

Matos, Maria Izilda de (2001). Por uma história das sensibilidades: em foco a masculinidade. História Questões \& Debates, 34, 45-63. Recuperado de https://revistas.ufpr.br/historia/ article/view/2658

Mbembe, Achille (2011). Necropolítica. Em Necropolítica seguido de sobre el Gobierno Privado Indirecto (pp. 17-76). Barcelona: Melusina. Recuperado de https://aphuuruguay.files. wordpress.com/2014/o8/achille-mbembe-necropolczadtica-seguido-de-sobre-el-gobierno-privado-indirecto.pdf

Mbembe, Achille (2017). Necropolítica. Arte e ensaios, 2(32), 123-151. Recuperado de https:// revistas.ufrj.br/index.php/ae/article/view/8993/7169

McRobbie, Angela (1978). Working Class Girls and the Culture of Femininity. Em Women take issue (pp. 35-6o), editado por Women's Studies Group. London: Hutchinson. Recuperado de https://link.springer.com/chapter/10.1007/978-1-349-21168-5_3

Melgaço, Paulo; Caetano, Marcio; Goulart, Treyce (2016). Masculinidades hegemônicas e dissidências: tensões curriculares em cotidianos de escolas da periferia. Revista Reflexão e Ação, 24(1), 214-232. https://doi.org/10.17058/rea.v24i1.6851

Moita Lopes, Luiz Paulo (2002). Identidades fragmentadas: a construção discursiva de raça, gênero e sexualidade em sala de aula. Campinas: Mercado das Letras.

Patto, Maria Helena (2009). De gestores e cães de guarda: sobre psicologia e violência. Temas em Psicologia, 17(2), 405-415. Recuperado de http://pepsic.bvsalud.org/scielo.php?scrip$\mathrm{t}=\mathrm{sci} \_$arttext\&pid=S1413-389X2009000200012\&lng=pt\&tlng=pt 
Pinho, Osmundo (2004). Qual a identidade do homem negro? Democracia Viva, 22, 64-69. Recuperado de https://www.academia.edu/1420907/Qual_\%C3\%A9_a_identidade_do_homem_negro

Pinho, Osmundo (2014). O fantasma do Estado: genocídio e necropolítica. Recuperado de http:// reajanasruas.blogspot.com.br/2014/o7/o-fantasma-do-estado-genocidio-e.html

Quijano, Aníbal (1992). Notas sobre a questão da identidade e nação no Peru. Estudos Avançados, 6(16), 73-80. https://dx.doi.org/10.1590/So103-40141992000300007

Quijano, Aníbal (1995). “Raza”, “etnia” y “nación” en Mariátegui: cuestiones abiertas. Estudios Latinoamericanos, 2(3), 3-19. Recuperado de http://www.revistas.unam.mx/index.php/rel/ article/view/49720/44717

Quijano, Aníbal (2005). Colonialidade do poder, eurocentrismo e América Latina. Em A colonialidade do saber: eurocentrismo e ciências sociais. Perspectivas latino-americanas (pp. 227-278), editado por Edgardo Lander. Buenos Aires: Clacso. Recuperado de http://bibliotecavirtual. clacso.org.ar/ar/libros/lander/pt/Quijano.rtf

Rezende, Andréia; Carvalho, Marília (2012). Formas de ser menino negro: articulações entre gênero, raça e educação escolar. Em Diferenças e desigualdades na escola (pp. 31-54). Campinas: Papirus.

Rosemberg, Fúlvia (2001). Escola formal, mulher e gênero no Brasil contemporâneo. Revista Estudos Feministas, 9(2), 515-540. Recuperado de http://www.scielo.br/scielo.php?pi$\mathrm{d}=$ s0100-15742002000100002\&script=sci_abstract\&tlng=pt

Rosemberg, Fúlvia (2002). Organizações multilaterais, Estado e políticas de educação infantil: History Repeats. Cadernos de Pesquisa, 115, 25-63. Recuperado de http://www.scielo.br/ pdf/cp/n115/ao2n115.pdf

Rosemberg, Fúlvia; Madsen, Nina (2011). Educação formal, mulheres e gênero no Brasil contemporâneo. Em O Progresso das Mulheres no Brasil 2003-2010 (pp. 390-434). Rio de Janeiro/Brasília: Cepia/ONU Mulheres.

Santomé, Jurjo Torres (2013). As culturas negadas e silenciadas no currículo. Em Alienígenas na sala de aula (pp. 159-177). Petrópolis: Vozes.

Souza, Raquel (2010). Rapazes negros e socialização de Gênero. Cadernos Pagu, 34, 107-142.

Vargas, João H. Costa (2010). A diáspora negra como genocídio: Brasil, Estados Unidos ou uma geografia supranacional da morte e suas alternativas. Revista da ABPN, 1(2), 31-65. Recuperado de http://www.abpnrevista.org.br/revista/index.php/revistaabpn1/article/ view/289/269 
Vargas, João H. Costa (2017). Por uma mudança de paradigma: antinegritude e antagonismo estrutural. Revista de Ciências Sociais. Fortaleza, 48(2), 83-105. Recuperado de http://www. repositorio.ufc.br/handle/riufc/2790o

Viveros-Vigoya, Mara (2018). As cores da masculinidade: experiências interseccionais e práticas de poder na Nossa América. Rio de Janeiro: Papéis Selvagens.

Viveros-Vigoya, Mara; Lesmes-Espinel, Sergio (2014). Cuestiones raciales y construcción de Nación en tiempos de multiculturalismo. Universitas Humanística, $77(77)$. Recuperado de https://revistas.javeriana.edu.co/index.php/univhumanistica/article/view/8o77

Viveros-Vigoya, Mara; Gutmann, Matthew (2007). Masculinidades en América Latina. Em Tratado de psicología social:perspectivas socioculturales (pp.120-138), coordenado por Miguel Angel Aguilar; Anne Reid. Barcelona: Anthropos.

Waiselfisz, Julio Jacobo (2012). Mapa da violência 2012: a cor dos homicídios no Brasil. Rio de Janeiro: Cebela/Flacso.

Walsh, Catherine (2010). Raza, mestizaje y poder: horizontes coloniales pasados y presentes. Crítica y Emancipación, 3, 95-124.

Walsh, Catherine (2008). Interculturalidad, pluralidade y decolonialidad: las insurgencias político epistémicas de refundar el estado. Tabula Rasa, 9, 131-152.

Welzer-Lang, Daniel (2001). A construção do masculino: dominação das mulheres e homofobia. Revista Estudos Feministas, 9(2), 460-482. http://dx.doi.org/10.1590/So104026X2001000200008

Willis, Paul (1977). Learning to Labour: How Working-Class Kids get Working Class Jobs. Aldershot: Saxon House.

Woodward, Kathryn (2009). Identidade e diferença: uma introdução teórica e conceitual. Em Identidade e diferença: a perspectiva dos estudos culturais (pp. 7-72). Petrópolis: Vozes. 